\title{
ANTi-VACCine Misinformation AND THE LAW: Challenges and Pitfalls
}

\author{
DORIT RUBINSTEIN REISS \\ Partial Transcript of the Virtual Grand Rounds Summer Series Lecture*
}

June 25, 2020

PROFESSOR REISS: Thank you for having me, and I am overwhelmed by this introduction. Also, like you, I hope that everybody is staying safe. My focus today is: what legal tools do we have to handle outbreaks that can be traced to misinformation? Most of my talk will focus on anti-vaccine misinformation because that is where I started looking at this. I will end the talk with some reference to COVID-19 misinformation, which is a growing public topic.

I want to mention that my family owns some regular stock in GSK, which is a vaccine manufacturer. I am not sure that is related to what I am talking about today, but it is better to have more disclosure than less.

Imagine the following scene. An anti-vaccine organization puts out misinformation that deters people from vaccinating. This could lead to an outbreak. For example, if you look at the bottom of the slide, this is a graph of cases of measles in the United States over the past decade. ${ }^{1}$ If you look at it, you will see that over the past few years we have had several large outbreaks that can be traced to anti-vaccine misinformation. This is the kind of harm that can result from misinformation. An unvaccinated child can get sick. The parents may consider suing the people that convinced them not to vaccinate. Also, an unvaccinated child can get sick and infect someone else. In this case, the family of the newly infected person may want to sue the organization for promoting this information. Moreover, an outbreak can cause colossal harm to a community, and the state public health department may want to remedy the misinformation on behalf of the community.

The Minnesota measles outbreaks are examples of how vaccine misinformation can harm communities. Minnesota had one of the largest Somali immigration communities in the United States. When the community came in, they had very high rates of vaccination. In $2004,92 \%$ of Somali children were vaccinated against measles, mumps, and rubella with the MMR vaccine. Later, a study suggested that autism rates in the community were high. This led to concerns about autism. Then, rumors spread around the community that the MMR vaccine created autism. These rumors spread through online research by members of the community and anti-vaccine groups. As a result, the rates of

* Indiana Health Law Review and the William S. and Christine S. Hall Center for Law and Health at the Indiana University Robert H. McKinney School of Law give special thanks to Professor Dorit Rubinstein Reiss for participating in the Virtual Grand Rounds Summer Series and providing her perspective on anti-vaccine misinformation. Professor Reiss is a Professor of Law at the University of California, Hastings College of the Law.

1. Measles Cases and Outbreaks, Ctr. For Disease Control \& Prevention (Nov. 5, 2019), https://www.cdc.gov/measles/cases-outbreaks.html [https://perma.cc/ZL94-6JLK]. 
MMR vaccination dropped to $42 \%$. Unsurprisingly, outbreaks formed. ${ }^{2}$

In 2011, the first outbreak happened. A thirty-month-old unvaccinated child traveled to Kenya. The child returned with measles and infected twenty other children. Seven of these children were too young to vaccinate, and nine others were left unvaccinated by choice. ${ }^{3}$ Further, fourteen of these children were hospitalized, and one of them ended up in the emergency room. Nonetheless, the anti-vaccine efforts in the community did not stop. At the time of this outbreak, the rate of MMR vaccination in the community was 54\%. It dropped further.

In 2017, the second and bigger outbreak happened. An unvaccinated child from the first case infected others. At the end of the day, there were seventy-five cases in this outbreak. Sixty-one of them were young Somali children. Most of these children were unvaccinated. Twenty-one of the children, many of them toddlers, were hospitalized. ${ }^{4}$

At the time when the anti-vaccine groups began speaking to the Somali community, there were already a lot of studies asking whether MMR causes autism. A large study in Denmark found no difference in rates of autism between children who got the MMR vaccine and children who did not. Similarly, a study of over 500,000 children in Finland found no link either. ${ }^{5}$ A smaller study in the United Kingdom and a large study in Japan also found no link. ${ }^{6}$ Further, a study in Canada found no link. ${ }^{7}$ So, at the point we are talking about, there were already a lot of studies that looked at whether MMR causes autism. Even before the 2017 outbreak, a study in the United States looked at 95,000 children and found no link between MMR and autism. ${ }^{8}$ For completion, I will add that another large study from Denmark found no link between the two. ${ }^{9}$ So, you can say quite reasonably that the claim that MMR causes autism, at that point, was strongly disproved by many cities around the world. However, misinformation was intentionally spread in communities by anti-vaccine groups. As a result, MMR vaccination rates dropped, and outbreaks put children in the hospital.

2. Dorit Rubinstein Reiss \& John Diamond, Measles and Misrepresentation in Minnesota: Can There Be Liability for Anti-Vaccine Misinformation That Causes Bodily Harm?, 56 SAN DIEGO L. REV. 531, 532 (2019).

3. Id. at 551 .

4. Id. at 552 .

5. Annamari Ma“kela" et al., Neurologic Disorders After Measles-Mumps-Rubella Vaccination, 110 PEDIATRICs 957, 957 (2002).

6. Brent Taylor et al., Autism and Measles, Mumps, and Rubella Vaccine: No Epidemiological Evidence for a Causal Association, 353 LANCET 1985, 2026 (1999); Hideo Honda et al., No Effect of MMR Withdrawal on the Incidence of Autism: A Total Population Study, $46 \mathrm{~J}$. Child. Psychol. Psychiatry 561, 572 (2005).

7. Eric Fombonne et al., Pervasive Developmental Disorders in Montreal, Quebec, Canada: Prevalence and Links with Immunizations, 118 PeDIATRICS e139, e139-40 (2006).

8. Anjali Jain et al., Autism Occurrence by MMR Vaccine Status Among US Children with Older Siblings with and Without Autism, 313 JAMA 1534, 1534 (2015).

9. Anders Hviid et al., Measles, Mumps, Rubella Vaccination and Autism: A Nationwide Cohort Study, 170 AnNals Internal Med. 513, 513 (2019). 
When someone spreads misinformation that can be linked to disease, what can we do? Since I am a law professor, I will talk about the legal tools for this. The first tool for responding to misinformation is not a legal tool. It is education, which includes providing correct information and debunking misinformation. Law is another set of tools. It is important to have a lot of tools in your toolbox.

Now, I am going to set out a number of tools that you can use. However, just because you can does not always mean that you should. Although we have legal tools available for when misinformation causes an outbreak or a disease, it is not always right to use them. Sometimes it will be appropriate, and sometimes it will not. Right now, I am going to talk about if we can use legal tools. Whether we should is a policy question on the ground for the right case.

So, what can we do? What tools do we have? The first potential claim I want to cover is the claim of misrepresentation or fraud. ${ }^{10}$ Intentional misrepresentation or fraud first requires that you show a material misrepresentation, meaning you knew or recklessly disregarded something. Reckless disregard does not mean that you just were very negligent. It means that there are grounds to think that you had a suspicion that it was fraud or that you intentionally ignored information that something was wrong. Knowledge or reckless disregard as to its truth or falsity is the second requirement. Intent to induce reliance is the third requirement. Justifiable reliance by the victim is the fourth requirement, and pecuniary damages by the victim are the final requirement.

Remember, there are two kinds of claims that you can bring here. One is a claim for someone who did not vaccinate or was infected by someone who did not vaccinate for physical harm. The other claim is a claim of costs by the department of health.

I want to point out something. Many anti-vaccine groups or individuals sincerely believe in the information that they provide. So, many of the people that claimed MMR caused autism probably believed that. They did not know that the information was false. And, while you can say that they were at least negligent for ignoring many studies, they sincerely believed that what they were saying was true. So, this is a tricky claim to make.

Another issue that I want to point out is whether we have justifiable reliance by the victim. If your doctor tells you that you should vaccinate your child with MMR and an anti-vaccine organization tells you that you should not, is it justifiable to rely on what the anti-vaccine organization said over what your doctor said? Not necessarily.

Finally, another problem with misrepresentation or fraud is that it is focused on financial damages, rather than physical damages.

On the other hand, you may ask whether you can use intentional misrepresentation for the costs to the department of health. The department of health is claiming that the anti-vaccine organization misrepresented information. And, as a result, it lost money because it had to put in costs to address the public health issue. This was actually tried by funds for tobacco. As you hopefully know, tobacco companies were shown to misrepresent quite a bit of information.

10. See Reiss \& Diamond, supra note 2 . 
Specifically, they hid or misrepresented information about how addictive and harmful cigarettes were.

In the 1970s and 1980s, a lot of actors and hedge funds tried to take tobacco companies to court. One such case is New Jersey Carpenters Health Fund v. Philip Morris, Inc. ${ }^{11}$ Such was addressed in the District Court of New Jersey in 1998.

In New Jersey Carpenters Health Fund, the claim was that the tobacco companies committed intentional misrepresentation against the health fund by misrepresenting information to people who smoked tobacco. The problem with that claim was that the court said that the tort of intentional misrepresentation was to protect the victim from misinformation, not third parties or those who had later costs from misinformation. Therefore, the courts routinely rejected these kinds of claims by health funds. So, trying to sue through the department of health using intentional misrepresentation may be unsuccessful. It is important to note that such is not a one-to-one because the health funds were also suing as the health insurer. Health departments are not quite in that role. However, the same logic that led courts to say that the health funds were too remote from intentional misrepresentation should lead to the courts saying that the health departments cannot sue for the public cause here.

Another potential claim, especially relevant to the people who got sick as a result of the anti-vaccine misinformation, is intentional misrepresentation that risks physical harm. This is embodied in section 310 of the Restatement (Second) of Torts. ${ }^{12}$ It has not been adopted in the Restatement (Third) of Torts yet. Nonetheless, the Restatement (Second) of Torts has this option. It says that if you misrepresent something, you can be held liable for physical harm if you intended for your statement to induce reliance, you knew that the statement was false, or you knew that you did not have the knowledge which you professed.

On one hand, we are running into the same problem we ran into when we talked about intentional misrepresentation in the economic sphere. Anti-vaccine people generally believe what they are saying. So, they do not know that the statement is false. They might know that other things are statements thought, but they do not know that the statement is false. You can ask whether they know that they do not have the knowledge that they profess. However, that can also be tricky to show. For example, if an anti-vaccine activist believes that he knows something that a doctor does not, then he does not know that he lacks the knowledge. Remember, this is an intentional tort. You need to have subjective intent, and that will be really hard to show here.

Another potential claim that does not have the problem of intentional torts is a public nuisance scheme. Public nuisance has been used in the public health context in a number of areas. ${ }^{13}$ It has been used to bring state claims against lead

11. New Jersey Carpenters Health Fund v. Philip Morris, Inc., 17 F. Supp. 2d 324 (D.N.J. 1998).

12. Restatement (SeCOnd) of Torts $\S 310$ (Am. Law InSt. 1965).

13. Lindsay F. Wiley, Rethinking the New Public Health, 69 WASH. \& LEE L. REV. 207, 238 (2012). 
paint manufacturers. It has been used to bring claims against tobacco companies. Unreasonable interference with something common to the public, such as public health, is at the heart of public nuisance.

It is not impossible to think about the health department bringing a claim against a public health organization based on a public nuisance. But there are some barriers. One barrier is that, in the cases where it has been used in the past, public nuisance was used against a company that was creating a product. Now, you can say that there is nothing in the tort that is only directed against for-profit companies. That is fair. However, information is not the same as physical products. Information is harder to contain. It is closer to the realm of speech than the realm of conduct. Therefore, this might be a tricky tool to use for misinformation by itself. That said, we do have a past of using this in the public health context, and that might help.

Also, public nuisance is now being used in climate change. ${ }^{14}$ Several lawsuits on climate change or the opioid crisis are trying to use public nuisance. This is closer to the product area than misinformation. $\S$

Earlier we saw section 310 of the Restatement Second of Torts, which was about intentional misrepresentation that causes physical harm. On the other hand, section 311 of the Restatement Second of Torts is about negligent misrepresentation that causes physical harm to another. ${ }^{15}$ So, you do not have to show that the person promoting the misinformation knew that it was false.

For section 311, you first have to have a negligent misrepresentation. In terms of the Minnesota outbreak, you would probably have a strong misrepresentation claim since there were many studies that showed that the MMR vaccine was not linked to autism. Also, you can probably claim that it was negligent to say given that there was a global consensus that the MMR vaccine did not cause autism. So, you can show negligent misrepresentation.

As I said earlier, you have the following question: is it reasonable to rely on misinformation by anti-vaccine groups, rather than on what a doctor says? This is the second element for negligent misrepresentation that causes harm to another. In the Minnesota case, there is probably a good argument for reasonable reliance. In that case, you have anti-vaccine people who are very well-educated and wellspoken come in. Also, they brought Dr. Andrew Wakefield with them. Wakefield was a British gastroenterologist. He lost his license and suffered other consequences after a study he published, which implied that there was a link between the MMR vaccine and autism, was fraudulent. Though, his loss of the license was not due to the fraudulent study. It was due to his concealment of conflicts of interests, a couple of untrue statements, and performing invasive tests on children without good cause.

Nevertheless, when Wakefield spoke to the Minnesota community, he appeared as a doctor and was well-spoken. Therefore, it might be reasonable to rely on him. Other speakers in the community also sounded like they knew what

14. See Victor Flatt \& Richard O. Zerbe, Climate Change Common Law Nuisance Suits, 49 ENVTL. L. 683 (2019).

15. Restatement (SeCOnd) of Torts $§ 311$ (Am. Law Inst. 1965). 
they were saying. So, when you have a group of people who appear to know what they are saying, it might be reasonable to rely on them.

The third element of negligent misrepresentation that causes physical harm is that you have to show physical harm as a result. For the Minnesota case, this is easy. The measles outbreak hospitalized many kids.

Further, the fourth element is that you have to show a duty of care. In that sense, they collapse this tort with regular negligence for the purpose of misinformation. So, you have to show a duty. A duty can be created by your actions or by the relationship between you and the party. Accordingly, these cases were looking for a relationship between the speaker and the recipient of information that was closer than the general public just getting information.

Finally, the courts are also concerned about First Amendment limits. This is the fifth and final element. When we are talking about misinformation, we are talking about speech. The First Amendment protects freedom of speech, but you do have tort liability for speech offenses in some cases. Therefore, in those cases, where do you draw the line? The courts, convincingly, drew the line by saying that there is an area where you have a duty. As a result, the First Amendment is probably weakened when you show both the duty and the misrepresentation. Basically, we are looking for this overlap.

The goal of the courts is not to have too expansive of a tort. There are at least three concerns that they have with this tort. First, there is a First Amendment concern. The courts say we would rather err on the side of more speech rather than less. Tort liability could chill speech and impose consequences on it. Second, courts are worried about expansive liability. Generally speaking, negligence is not intent. It is less culpable, and the courts say that we are not going to allow unlimited liability when we are talking about languages. The problem with information is that it is spread easily. So, if you say something that is not true, it can spread very broadly and liability can easily become unmanageable. Finally, the courts felt unable to distinguish misinformation from things that are not quite misinformation. So, they are cautious there.

In our paper, we suggest two principled ways to allow the tort to operate in some cases but still remain limited so as to not jeopardize the First Amendment or lead to unlimited liability. Here is our suggestion. We think it is appropriate to impose liability on misinformation that causes harm, including outbreaks in some cases but not in others. The first limit we would impose depends on the relationship. We think it is more justified to impose liability when you have a one-on-one situation or when you are getting near a one-on-one situation. However, you also have mass media. For example, what happens when you are dealing with a small group? Let's say an anti-vaccine group brings in a speaker and has an audience of sixty people. Is it a private consult or mass media like the internet? There is some vagueness here and some areas where this will be harder to apply.

So, why do we think that this is a good standard? First of all, if you are speaking to someone one-on-one, you kind of see who is relying on you. You expect that the people you are trying to convince will rely on you when you are speaking to them face-to-face. When you are cultivating someone or in a relationship of consultation, you know that they are going to rely on you or at 
least you hope that they are going to rely on you. Therefore, you know who is relying on you. So, it is easier to say that you are liable because you looked them in the eye, told them something that was not true, and they got hurt.

On the other hand, when you post on the internet, you do not know who is reading your post. You do not know if there are reasonable grounds to expect that a person will rely on your post. So, you might argue that the person should fact check what you said, even if you think it is true. After all, you are not a doctor. The liabilities for private consults and small groups are well-defined. The same cannot be said for mass media. When you put something on the internet, many people can read it and liability can easily balloon.

Also, duty is often found when there is a relationship. So, this fits with what we do in other areas, and we do look for consistency in the law. We would like to have a similar approach across all areas. However, there are some problems with this approach. One problem is that, in a sense, you are rewarding the people who reached a larger audience. You are saying that because their misinformation went so broadly, they are off the hook. That is jarring. Maybe the person who misled more people should have a higher penalty and not be off the hook? It is also not directly related to the other elements of the tort of misrepresentation and so forth. But still, because we care about freedom of speech and worry about a not overextending liability, this gives us a principled way to draw some lines. When an anti-vaccine organization comes into a community and targets small groups, we are more likely to find liability on them.

Obviously, the law does not necessarily stop with one line. In imposing liability, in addition to the core continuum here, it is probably reasonable to also consider the level of culpability. If someone was very close to lying intentionally, we can treat them more severely than if it was an unreasonable and understandable error. So, culpability matters and should be taken into account.

The second factor is much trickier: how sophisticated is a target? This is trickier because it is very easy to insert bias into this element. When we are talking about very young children, we can say that their lack of sophistication makes us want to protect them more. Therefore, we will more easily find liability when children are targeted. However, once you move beside that, there is a danger. The Minnesota outbreak shows this danger very well.

If we are saying that the Somali community was less sophisticated, are we engaging in bias? We probably are to some degree. On the other hand, there is a good argument that, in terms of knowing who to rely on in the country, immigrant communities are more vulnerable than native communities. Though, we need to be very cautious in addressing the sophistication of a target. I think it is relevant, but I would be really cautious in applying it.

Everything I have said so far probably applies to some types of information and not to others. For example, in product liability, we have a tradition of penalizing and imposing liability on bad warnings for instructions. This is speech. However, instructions describe how to use a product. And, when you are describing how to use a product, you are getting closer to conduct and farther away from speech. Therefore, we would not be as worried about freedom of speech, and we would be able to impose liability if your instructions were negligent and caused a harm. 
Sponsored activity is even farther away from speech. An example of a sponsored activity is organizing a competition or a course. In a course, you are giving information. However, organizing a course is also an activity. If you manage a course in a way that puts people in danger because of how it is managed, such is closer to activity than speech.

Moreover, engaging in speech about what is dangerous is where we really want to be cautious and impose a liability in certain circumstances. We do not want to impose liability in all circumstances because a lot of speech can suggest dangers, and we want issues to be debated and exposed to the marketplace of ideas. If we are quick to impose liability, new ideas might face higher barriers.

So, negligent misrepresentation that causes harm is a viable option for tort liability in some cases. However, we are going to want to be careful. If somebody gives instructions, we can probably be pretty comfortable in imposing liabilities on instructions that were negligently false. If someone is just talking about riskbenefit, we are probably more likely to impose liability if the context is a consultation and not a mass media context.

What else can we do? We could consider reducing the protections for social media companies against liability. Right now, under section 230 of the Communication Decency Act, social media companies are protected from liability for civil liability. ${ }^{16}$ We could reduce that. For example, if Facebook put out antivaccine misinformation and someone got hurt, it could be liable. That is a little tricky in two ways. First, it can really limit what social media companies can do. Facebook has over a billion users. Regulating all of those users is probably not feasible in real-time. There are going to be limits to what Facebook can do. Also, civil liability may mean that Facebook would completely shut down scenarios of discussion. That is not necessarily a good thing. Second, we are penalizing Facebook for things where other people are more culpable. We are not cutting the promoters of misinformation out.

Another tool we may want to consider using is no-fault options. In an earlier paper, we wrote about the ability to impose taxes or fees on people who do not vaccinate. ${ }^{17}$ The logic is that even if we ignore fault, people who choose not to vaccinate are choosing to impose costs on others. Requiring them to internalize that cost can change their behavior and lead to a more equitable result as they will cover the costs that they would impose on others. This can include a fee for not vaccinating that would go into a special fund. The fund would cover the costs of people who are infected by unvaccinated individuals or the cost to the health department. This can also include a tax on not vaccinating. Similarly, such would go to a fund. Further, tax breaks could be offered to people who vaccinate.

We can also consider increasing insurance payments. However, there is a legal problem here, which is that the Affordable Care Act limits what you can impose a premium for. So, to allow this to happen, you would actually have to change the Affordable Care Act. Alternatively, you can give an insurance

16. 47 U.S.C. $\S 230$ (2020).

17. See Charlotte A Moser et al., Funding the Costs of Disease Outbreaks Caused by NonVaccination, 43 J.L. MED. \& ETHICs 633 (2015). 
discount to people who do vaccinate. There is a legal path to do this because the Affordable Care Act does allow the reduction of premiums for wellness plans.

The other way to go about using a no-fault issue is after the fact. You can bill or fine people who do not vaccinate if such causes an outbreak. There is nothing unconstitutional or illegal with this approach. In fact, this idea was modeled on an Arizona law, which says that the state can bill people if they knowingly go to a flood area, get caught there, and call for help. The same approach can be taken with non-vaccination. However, can you also do this for misinformation - not for the people who do not vaccinate but for the people who spread misinformation? Doing this would be a little tricky due to the First Amendment. You would be billing these people for the effect of their speech. Nonetheless, I think there is a good case for doing this for two reasons.

First, if the organization directly discouraged people from vaccinating, such would be an instruction. We penalize people for instructions. This is not a freedom of speech issue because instructions are very close to conduct. On the other hand, if an anti-vaccine advocate says that you can vaccinate your child, but also tells you that horrible things will happen to your child if you do, this is closer to negligent misrepresentation. You would probably be able to bill the antivaccine advocate, and you would be more likely to survive First Amendment scrutiny for a one-on-one consultation scenario.

Now, let's pull it back to COVID-19. So far, my main example has been antivaccine efforts in Minnesota. What is going on with COVID-19? You have probably noticed that there is a lot of misinformation about COVID-19. I want to split that misinformation into two kinds of misinformation. One type of misinformation tries to convince people how to treat COVID-19. In the pretty early days, an anti-vaccine group recommended vitamin $\mathrm{C}$, hyperbaric oxygen treatment, and zinc to cure COVID-19. Similarly, another anti-vaccine group recommended hydroxychloroquine and vitamin $\mathrm{C}$ as COVID-19 cures. Now, remember, the FDA recently revoked the emergency-use authorization for hydroxychloroquine because increasing evidence suggests that it does not do anything for COVID-19. During the early days, there may have been reason to think that it could have, but now we are at the point where the data does not support that thought.

If you promote a cure and someone uses that cure, there can be one of two results. Result one, the cure can harm the person. For example, hydroxychloroquine can harm you and cause a heart attack. Result two, the cure does not directly hurt you, but it also does not help you. You have been given false hope, which may make you less cautious and less avoiding of COVID-19.

The first result is probably much easier to address legally than the second. Under the first scenario, we are directly harmed by something that someone presented to us as a cure. At the very least, you can say that someone who promoted vitamin $\mathrm{C}$ as a cure for COVID-19 was acting without evidence, against the expert advice, and probably negligently. Hyperbaric oxygen treatment even more so. That is a treatment for people who have deep water sickness and not COVID-19.

As for the cure not protecting you, that is going to be a lot harder to prove. First, if the issue is "I was not as careful and got COVID-19 because I trusted that 
there was a cure," well, I could have gotten COVID-19 anyway. Causation is going to be an issue. Second, relying on a magic cure that experts recommend against might be seen as unreasonable reliance. So, that is one set of potential claims and their challenges.

I am going to use my last few minutes to address the different types of claims we are hearing about COVID-19, including that it is not dangerous or that you do not need to wear a mask. So, Candace Owens, who is a political activist, suggested that COVID-19 deaths are fake. Here is one of her tweets. She suggests the number of people dying from COVID-19 is false. Can you do anything about this? The risk here is that if you convince people that coronavirus is not dangerous, then a person might not be as careful. This would be a hard claim.

First of all, even if you are careful, you can still catch COVID-19. You could, however, claim that taking more precautions would reduce your risk. Though, this is really going to be very heavily fact-dependent. Second, is relying on a tweet by a person who is not a doctor reasonable? Again, you run into a problem. This is not an instruction. Candace Owens is not telling you to go out and catch COVID19. She is saying that the deaths from COVID-19 are fake and that it is not that big of a deal. Contrast this with an anti-vaccine leader who is encouraging people to catch COVID-19. The anti-vaccine leader has a whole set of claims. He suggests that the people who die from COVID-19 smoked, did not eat well, or were not in good health. Further, he argues that COVID-19 is just a common cold and that people need to go out to catch it. This is different because it is an instruction. The anti-vaccine leader is telling people to seek the virus. If you go out, catch COVID-19, and are harmed or infect someone else, then this is a good argument for misrepresentation that caused bodily harm. The only question will be: is it reasonable to rely on an anti-vaccine activist without relevant training? You could argue that he seemed convincing. He spoke with passion. A lot of people listen to him. The argument might be hard, but it is possible.

And we will stop here. 